\title{
Plexiform Neurofibroma of Nasal Tip
}

\author{
Rajanala Venkata Nataraj, Mohan Jagade, Kartik Parelkar, Reshma Hanawte, \\ Arpita Singhal, Dev Rengaraja, Kiran Kulsange, Kartik Rao, Pallavi Gupta \\ Department of Ear, Nose \& Throat and Head \& Neck Surgery, Grant Government Medical College, Mumbai, \\ India \\ Email: nataraj.rv@gmail.com
}

Received 27 September 2015; accepted 20 November 2015; published 23 November 2015

Copyright (C) 2015 by authors and Scientific Research Publishing Inc.

This work is licensed under the Creative Commons Attribution International License (CC BY).

http://creativecommons.org/licenses/by/4.0/

(c) (i) Open Access

\section{Abstract}

Neurogenic tumor is the name given to any tumor that arises from the nerve tissue or its coverings. Neurogenic tumors of Sino-nasal cavity are a very rare entity. The most common types are Schwannomas and Neurofibromas and the plexiform subtype is one form of these neuroendocrine tumors. We report the case series of two such cases of a plexiform neurofibroma of the nasal tip, which were excised via an open rhinoplasty approach.

\section{Keywords}

Plexiform Neurofibroma, Schwannoma, Nasal Tip, External Nasal Deformity, Open Rhinoplasty

\section{Introduction}

The first reported cases of external nasal neurogenic tumors were reported by New and Devine in 1947 and Das Gupta et al. in 1969 [1] [2]. In these cases, the neuroendocrine tumors were found at alar cartilages and tip of the nose, respectively. In these articles, the terms Neurofibroma and Schwannomas were used synonymously as they were considered to be same clinical entity. In 2007, Rameh et al. published an article claiming to report the first case of Solitary Plexiform Neurofibroma of Nasal Tip, which was excised by the method of Open Rhinoplasty [3]. The rest of reported cases of neurogenic tumors of nasal tip have been proven to be Schwannomas.

We hereby report two cases of Solitary Plexiform Neurofibroma of Nasal Tip.

CASE-1. A 18 years old female presented to us, in 2014, with a slowly growing mass over nasal tip since past 9 years. There were no complaints of pain, nasal obstruction or epistaxis. Several courses of antibiotics were tried out with no visible effect. The patient didn't notice any other similar kind of swelling elsewhere on the body. There was no past history of trauma to nose or any form of surgical intervention. Family history was negative for similar complaints.

On examination, a soft, non tender $4 \mathrm{~cm} \times 4 \mathrm{~cm}$ mass was seen over the tip and supratip area. The mass was 
non mobile and fixed to the alar cartilages. Anterior rhinoscopy and diagnostic nasal endoscopy were unremarkable. There was no evidence of café-au-lait spots and any other skin lesions (Figure 1 and Figure 2).

MRI of the mass showed an ill defined mass over the nasal tip which was abutting the alar cartilages (Figure 3). The mass was the biopsied and histopathological report was suggestive of neurogenic tumor, most probably neurofibroma.

The patient was then planned for open rhinoplasty and excision of the mass. Intra-operatively a non encapsulated mass was seen adherent to the alar cartilages. Careful dissection was done and mass was excised, without damaging the alar cartilages (Figure 4). Immediate post operative pictures were taken which showed markedly improved facial aesthetics. Final histopathology report revealed Plexiform variety of Neurofibroma composed of spindled cells with wavy, darkstaining nuclei and scanty cytoplasm, in a background of wavy collagen fibres, myxoid stroma and mast cells (Figure 5 \& Figure 6). Unfortunately patient was lost to follow up, because of personal reasons.

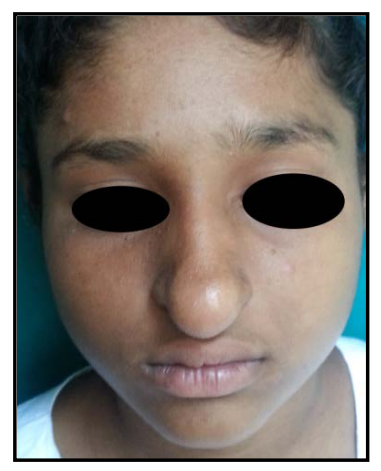

Figure 1. Frontal view.

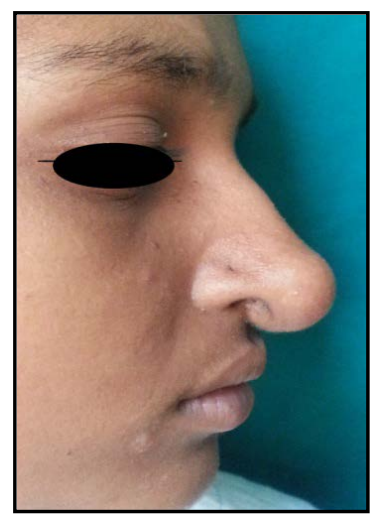

Figure 2. Lateral view.

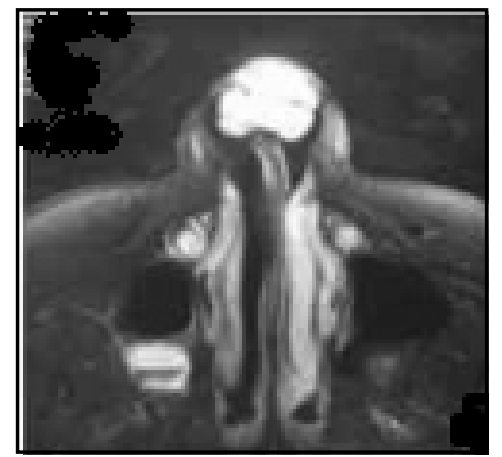

Figure 3. MRI showing hypodense mass lesion involving nasal tip. 


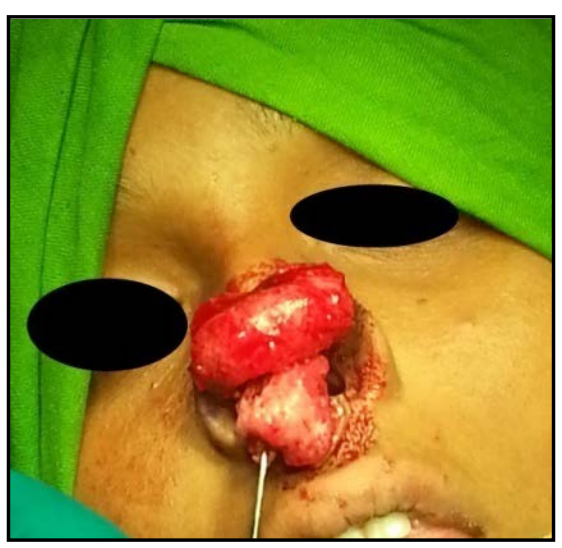

Figure 4. Intraoperative picture.

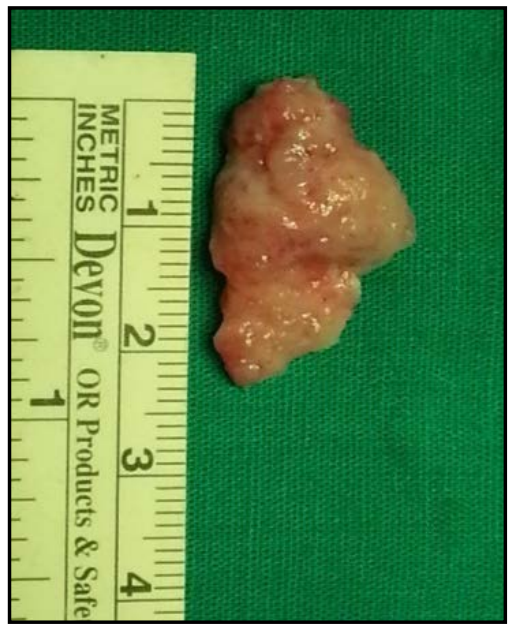

Figure 5. Resected specimen.

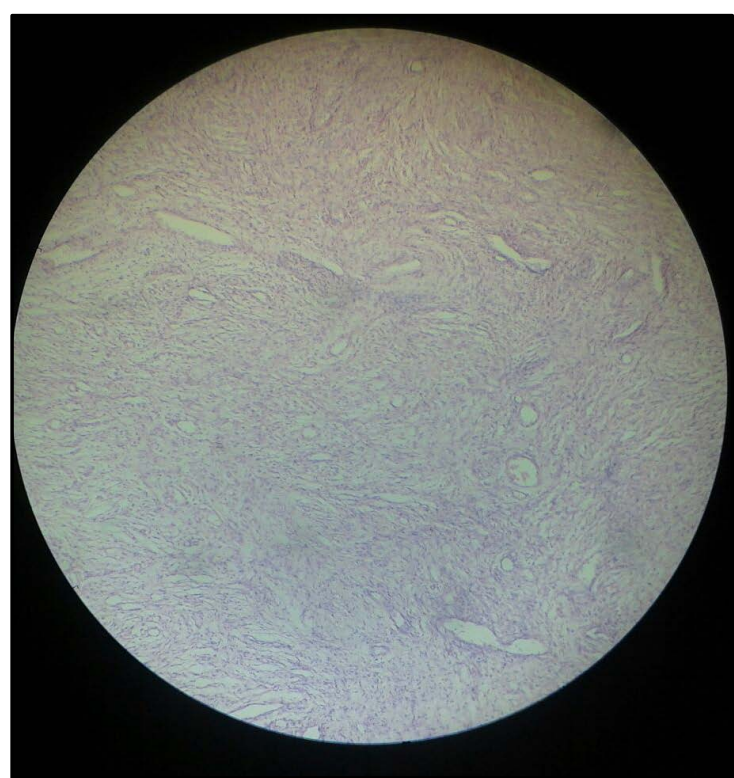

Figure 6. "Wavy" nuclei with bundles of collagen separated by a myxoid, degenerated stroma. 
CASE-2. A 23 years old female presented to us in 1996, with complaints of progressive slow growing mass over nasal tip since 15 years. Initially the mass was limited to the nasal tip but had progressed to an extent where the nasal tip had attained a drooped appearance and had crossed the lower lip (Figure 7 \& Figure 8). This also led to functional complications in form of bilateral nasal obstruction. Upon palpation the mass was non-tender, firm in consistency and mobile. Alar cartilages were intact but flattened. Anterior rhinoscopy examination revealed columella which was shortened and bent upon itself, collapsed alar cartilages with markedly compromised external nares. Unfortunately the patient did not have enough financial support to undergo MRI at that point of time. The mass was biopsied and was reported as neuroendocrine tumor.

The mass was then excised through an Open Rhinoplasty approach. Post operatively, the aesthetic result was excellent and there was no recurrence even after 1 year (Figure 9).

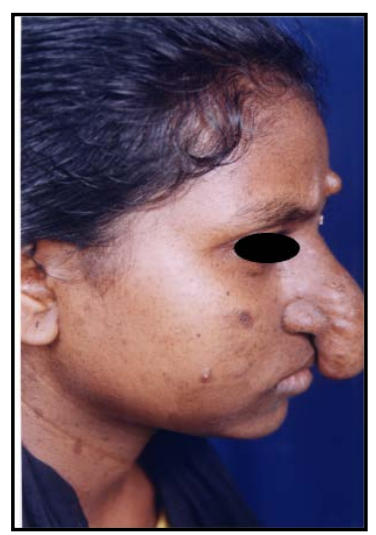

Figure 7. Lateral view.

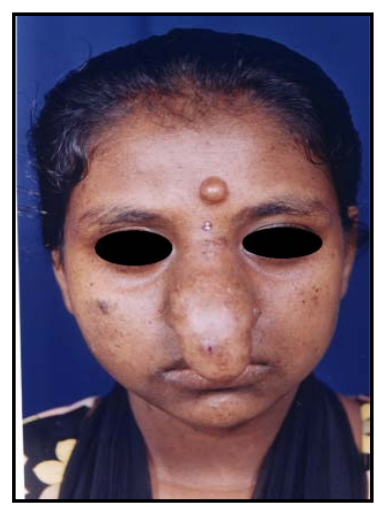

Figure 8. Frontal view.

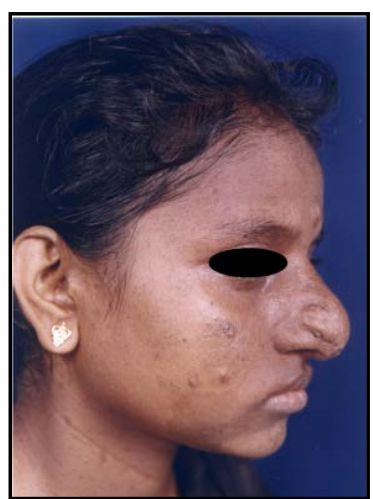

Figure 9. On 1 year follow up. 


\section{Discussion}

Neuroendocrine tumors were first recognized as pathological entities by Verocay et al. in 1908 [4]. The benign types include two closely related tumors viz Neurilemoma (Schwannoma) and Neurofibroma. Ninety percent of these tumors are benign, around two-thirds being Schwannomas and one-third Neurofibromas [5]. Till late 1960s, these two terms were considered synonymous and were used interchangeably [1] [2]. However, later on, it was discovered that these two tumors have different cells of origin. Schwannomas tend to be encapsulated and contain a more homogenous population of differentiated neoplastic Schwann cells, whereas, Neurofibromas are not encapsulated and composed of a heterogenous cell population of Schwann cells, perineural hybrid cells and intraneural fibroblasts [6] [7]. It is a well established fact that Neurofibromas are associated with Neurofibromatosis or Von Recklinghausen's disease. But our patients didn't have any associated lesions suggestive of Neurofibromatosis.

DasGupta et al. stated that benign solitary tumors arising in peripheral nerves can develop in every possible anatomic location [2]. Around one third develop in the head and neck area [8]. Neuroendocrine tumors in head and neck area, particularly nose, usually arise from microscopic branches of various nerves, which makes it very difficult to pin point the nerve of origin.

Neuroendocrine tumors of sino-nasal origin are a very rare occurrence. But amongst the few cases reported, most of the cases were diagnosed as Schwannoma [3].

Radiographically, neurofibromas and schwannomas both show high signal on T2-weighted images and a capsule can be detected around the schwannomas [9]. But a definitive diagnosis, regarding nature of the lesion can only be obtained by histological examination of surgical specimen. Apart from differences in histological appearance, schwannomas show intense immunostaining for S-100, a neural crest marker antigen, while neurofibromas stain less intensely [10].

The only treatment option available is surgical excision. As schwannomas arise from the edge of a nerve and are encapsulated, they can enucleated easily without damaging the nerve [2]. On the other end of the spectrum, plexiform neurofibromas are non-encapsulated diffuse, which makes complete en bloc resection difficult. Furthermore, as the radiosensitivity of these tumors is very low, possibility of recurrence of these tumors is very likely. One favorable feature of such tumors, is that their risk of malignant degeneration is very low, and therefore, unnecessary wide unaesthetic excisions are often not necessary [2].

\section{Conclusion}

Neuroendocrine tumors of sinonasal tracts are rare. They often present as painless midline swellings and a high degree of suspicion is required for their diagnosis. Plexifrom neurofibroma is non encapsulated and diffuse, which makes it difficult to resect and increases the chances of local recurrence. But due to low rates of malignant transformation, aggressive disfiguring incisions are not required.

\section{References}

[1] New, G. and Devine, K. (1947) Neurogenic Tumors of Nose and Throat. Archives of Otolaryngology, 46, 163-179. http://dx.doi.org/10.1001/archotol.1947.00690020172004

[2] DasGupta, T., Brasfield, R., Strong, E. and Hajdu, S. (1969) Benign Solitary Schwannoma (Neurilemomas). Cancer, 24, 355-360. http://dx.doi.org/10.1002/1097-0142(196908)24:2<355::AID-CNCR2820240218>3.0.CO;2-2

[3] Rameh, C., Husseini, S., Tawil, A., Fuleihan, N. and Hadi, U. (2007) Solitary Plexiform Neurofibroma of the Nasal Tip: Case Report and Review of the Literature. International Journal of Pediatric Otorhinolaryngology Extra, 2, 116119. http://dx.doi.org/10.1016/j.pedex.2007.03.003

[4] Verocay, J. (1908) Multiple Geschwulste als Systemerkrankung am nervosen Apparate. Festschrift fur Chiari, Wien and Leipzig, 378.

[5] Hillstrom, R.P., Zarbo, R.J. and Jacobs, J.R. (1990) Nerve Sheath Tumors of the Paranasal Sinuses: Electron Microscopy and Histopathologic Diagnosis. Otolaryngology Head and Neck Surgery, 102, 257-263.

[6] Berlucchi, M., Piazza, C., Blanzuoli, L., Battaglia, G. and Nicolai, P. (2000) Schwannoma of the Nasal Septum: A Case Report with Review of the Literature. European Archives of Oto-Rhino-Laryngology, 257, 402-405. http://dx.doi.org/10.1007/s004050000242

[7] Ferner, R. and O’Doherty, M. (2000) Neurofibroma and Schwannoma. Current Opinion in Neurology, 15, $679-684$. http://dx.doi.org/10.1097/00019052-200212000-00004 
[8] Wilson, J., McLaren, K., MdIntyre, M., von Haacke, N. and Maran, A. (1988) Nerve Sheath Tumors of the Head and Neck. Ear, Nose \& Throat Journal, 67, 103-110.

[9] Lemmerling, M., Moerman, M., Govaere, F., Praet, M., Kunnen, M. and Vermeersch, H. (1998) Schwannoma of the Tip of the Nose: MRI. Neuroradiology, 40, 264-266. http://dx.doi.org/10.1007/s002340050582

[10] Donnelly, M., Al-Sader, M. and Blayney, A. (1992) View from Beneath: Pathology in Focus, Benign Nasal Schwannoma. Journal of Laryngology and Otology, 106, 1011-1015. http://dx.doi.org/10.1017/S0022215100121644 